\title{
Does musical enrichment enhance the neural coding of syllables? Neuroscientific interventions and the importance of behavioral data
}

\section{Samuel Evans ${ }^{1 *}$, Sophie Meekings ${ }^{1}$, Helen E. Nuttall ${ }^{2}$, Kyle M. Jasmin ${ }^{1}$, Dana Boebinger ${ }^{1}$, Patti Adank ${ }^{2}$ and Sophie K. Scott ${ }^{1}$}

1 Institute of Cognitive Neuroscience, University College London, London, UK

${ }^{2}$ Speech, Hearing and Phonetic Sciences, University College London, London, UK

*Correspondence: samuel.evans@ucl.ac.uk

Edited by:

Lynne E. Bernstein, George Washington University, USA

Reviewed by:

Dorothy Bishop, University of Oxford, UK

Keywords: musicianship, speech perception, literacy, intervention, auditory brainstem response (ABR)

\section{A commentary on}

Music enrichment programs improve the neural encoding of speech in at-risk children

by Kraus, N., Slater, J., Thompson, E. C., Hornickel, J., Strait, D. L., Nicol, T., et al. (2014). J. Neurosci. 34, 11913-11918. doi: 10.1523/JNEUROSCI.1881-14.2014

Speech perception problems lead to many different forms of communication difficulties, and remediation for these problems remains of critical interest. A recent study by Kraus et al. (2014b) published in the Journal of Neuroscience, used a randomized controlled trial (RCT) approach to identify how low intensity communitybased musical enrichment for "at-risk children" improved neural discrimination of "ba/ga" syllables. In the study, forty-four children aged six to nine years from "gang reduction zones" received 2 hours of musical training each week arranged in two 1 hour sessions. A control group received a single year of training following a one year delay, whilst the experimental group received two full years of training without delay. They found that auditory brainstem responses (ABRs) to the "ba/ga" syllables were changed in the experimental group, but only after more than one year of training. ABRs were not changed in the control group, either following the delay or after the first full year of training. We endorse the use of a randomized control trial (RCT) to evaluate this educational programme, but argue that several additional criteria must be met before firm conclusions can be drawn about the benefits of the intervention.

Kraus et al. argue their results provide evidence that "community music programs may stave off certain languagebased challenges" (Kraus et al., 2014b, p. 11915), but this claim is hard to sustain without behavioral data (e.g., of concomitant improvements in speech perception or literacy). For the current paper, it would be necessary to show group differences in behavior that relate to the educational program, and explore the ways that individual differences in neural and behavioral profiles vary with the speech and literacy measures. This is particularly important given that a meaningful musicianship advantage in speech perception can be hard to demonstrate, as the size of the advantage shown for musicians (compared to non-musicians) is small $(<1 \mathrm{~dB})$ (Parbery-Clark et al., 2009) and has not been consistently replicated (Fuller et al., 2014; Ruggles et al., 2014). We also note a more recent follow up study (Kraus et al., 2014a) shows no improvement in literacy skills associated with active musical engagement.

There are other important issues: for example, Kraus et al. presented a single pair of synthesized "ba" and "ga" syllables 6000 times, at a rate of 4.35 repetitions per second, to each participant. No naturally occurring human speech sequences occur like this: speech tokens are never identical, and repetition itself is normally avoided as it is low in informational value (change, not repetition, conveys information) and leads to illusory percepts (cf. the verbal transformation effect, Pitt and Shoaf, 2002).

In addition, these items were synthesized speech tokens in which a single acoustic cue (the trajectory of the second format, F2) was manipulated. Notably, the major frequency difference where the F2s are maximally different between ba and ga $(900-2480 \mathrm{~Hz})$ are not investigated as the cross-phaseogram measurements are restricted to $900-1500 \mathrm{~Hz}$, due to a lack of phase locking above $1500 \mathrm{~Hz}$ (Aiken and Picton, 2008). This frequency "window" restricts the analysis to a range where the whole F2 sweep for "ba" is included, but most of that for "ga" is excluded from the analysis (see Figure in Supplementary Materials, Hornickel et al., 2009). This suggests that the response is not specifically discriminant per se, and may be associated with detection of the presence of "ba" stimuli. A contrast of "ba" with "da," which has a lower F2 sweep, would be a way to address this. To further develop our understanding of these ABR effects, it is also essential to understand how the measurements used in this study relate to the auditory brain stem and cortex measures used in other investigations, of the effects of musical training. Table 1 shows a summary of the ABR papers on musical training in children which illustrates the wide variety of measures used and their significance across studies. 
Table 1 | A summary of the ABR papers on musical training in children which illustrates the wide variety of measures used and their significance across studies.

\begin{tabular}{|c|c|c|c|c|c|}
\hline Paper & Age range & Stimulus & Musical training criteria & Measure & $\begin{array}{l}\text { Finding (relative to } \\
\text { non-musician/control group) }\end{array}$ \\
\hline \multirow[t]{4}{*}{$\begin{array}{l}\text { Strait et al. } \\
\text { (2012; Brain and } \\
\text { Language) }\end{array}$} & $\begin{array}{l}\text { School age } \\
\text { (7-13 years) }\end{array}$ & $\begin{array}{l}\text { Synthetic } 170 \text { ms } \\
\text { /da/ stimulus } \\
\text { presented with and } \\
\text { without multi-talker } \\
\text { babble noise }\end{array}$ & $\begin{array}{l}\text { Currently undergoing private } \\
\text { instrumental training, began } \\
\text { musical training by age } 5 \text { and had } \\
\text { practiced } \geq 20 \text { min at least } 5 \text { days } \\
\text { weekly for last } 4 \text { years }\end{array}$ & $\begin{array}{l}\text { cABR peak } \\
\text { timing }\end{array}$ & $\begin{array}{l}\text { First peak at the start of the formant } \\
\text { transition ( } 43 \mathrm{~ms} \text { ) faster in quiet and } \\
\text { in noise. No significant differences } \\
\text { between onset peak ( } 9 \mathrm{~ms} \text { ) or } \\
\text { steady-state vowel peak ( } 63 \mathrm{~ms} \text { ) in } \\
\text { quiet or noise }\end{array}$ \\
\hline & & & & & $\begin{array}{l}\text { Less of a quiet-noise timing shift in } \\
\text { formant peak ( } 43 \mathrm{~ms}) \text {, but not in } \\
\text { onset ( } 9 \mathrm{~ms} \text { ) or steady-state ( } 63 \mathrm{~ms} \text { ) }\end{array}$ \\
\hline & & & & $\begin{array}{l}\text { Fast Fourier } \\
\text { Transform }\end{array}$ & $\begin{array}{l}\text { Stronger encoding of summed } \\
\text { frequencies across range of } \\
200-800 \mathrm{~Hz} \text { in quiet and noise } \\
\text { conditions. No difference in strength } \\
\text { of fundamental frequency encoding } \\
\text { in quiet or noise }\end{array}$ \\
\hline & & & & $\begin{array}{l}\text { Stimulus- } \\
\text { response } \\
\text { correlation }\end{array}$ & $\begin{array}{l}\text { Significant difference in strength of } \\
\text { stimulus-response correlation in } \\
\text { noise for vowel region. No } \\
\text { significant difference in quiet. } \\
\text { Significant difference in quiet vs. } \\
\text { noise stimulus-response correlation } \\
\text { difference }\end{array}$ \\
\hline
\end{tabular}

Strait et al.

(2013;

Developmental

Cognitive

Neuroscience)
Preschoolers Synthetic $170 \mathrm{~ms}$

(3-5 years)

/da/ stimulus

presented with and

without multi-talker

babble noise
Currently undergoing private or group music training for minimum of 12 consecutive months before the study. Attending weekly classes and used materials to practice 4 times a week at home

\section{cABR peak Onset peak $(9 \mathrm{~ms})$ and formant timing transition (43 ms) faster in quiet and in noise. No significant difference in steady-state peak (63 ms) in quiet or noise. \\ Less of a quiet-to-noise timing shift for formant transition peak (43 ms), but no significant differences in quiet-noise timing shifts for onset (9 ms) or steady-state vowel (63 ms) peaks \\ cABR peak No absolute amplitude differences in amplitude quiet or noise conditions, nor a difference in quiet-noise amplitude reductions for onset $(9 \mathrm{~ms})$, formant (43 ms) or steady-state (63 ms) peaks}

Stimulus- No differences in stimulus-response response correlation strength across vowel correlation region in quiet or noise. No significant difference in quiet vs. noise stimulus-response correlation difference

Fast Fourier No differences in strength of Transform encoding at fundamental frequency or for frequencies summed across $200-800 \mathrm{~Hz}$ in either quiet or noise conditions 
Table 1 | Continued

\begin{tabular}{|c|c|c|c|c|c|}
\hline Paper & Age range & Stimulus & Musical training criteria & Measure & $\begin{array}{l}\text { Finding (relative to } \\
\text { non-musician/control group) }\end{array}$ \\
\hline $\begin{array}{l}\text { Strait et al. } \\
\text { (2014; Cerebral } \\
\text { Cortex) }\end{array}$ & $\begin{array}{l}\text { Preschoolers } \\
\text { (3-5 years) } \\
\text { and school } \\
\text { age ( } 7-13 \\
\text { years) }\end{array}$ & $\begin{array}{l}170 \text { ms synthetic } \\
\text { /ba/ and /ga/ stimuli }\end{array}$ & $\begin{array}{l}\text { Preschoolers: Currently } \\
\text { undergoing private or group } \\
\text { music training for minimum of } 12 \\
\text { consecutive months before the } \\
\text { study. Attending weekly classes } \\
\text { and used materials to practice } 4 \\
\text { times a week at home. } \\
\text { School age: Currently receiving } \\
\text { private lessons, started music } \\
\text { training by or before age } 6 \text {, and } \\
\text { had consistently practiced for a } \\
\text { minimum of } 3 \text { years for } \geq 20 \text { min } \\
\text { for at least } 5 \text { days weekly }\end{array}$ & $\begin{array}{l}\text { Cross- } \\
\text { phaseogram* }\end{array}$ & $\begin{array}{l}\text { Better phase differentiation between } \\
\text { /ba/ and /ga/ stimuli from } 15 \text { to } \\
45 \text { ms post-stimulus onset, } \\
\text { (corresponding to formant transition) } \\
\text { across frequency range } \\
900-1250 \mathrm{~Hz} \text { in preschoolers and to } \\
900-1500 \mathrm{~Hz} \text { in school-aged } \\
\text { children. No phase differences in } \\
\text { control vowel region }(60-170 \mathrm{~ms} \text { ) }\end{array}$ \\
\hline $\begin{array}{l}\text { Kraus et al. } \\
\text { (2014a; Frontiers } \\
\text { in Neuroscience) }\end{array}$ & $\begin{array}{l}\text { School-age } \\
\text { (7-10 years) }\end{array}$ & $\begin{array}{l}40 \mathrm{~ms} \\
\text { consonant-formant } \\
\text { transition /d/ } \\
\text { (perceived as /da/) }\end{array}$ & $\begin{array}{l}\text { Harmony Project music } \\
\text { appreciation: } 1 \mathrm{~h} \text { twice per week } \\
\text { pitch, rhythm, vocal performance, } \\
\text { improvisation, composition, } \\
\text { musical styles and notation, basic } \\
\text { recorder training. Some subjects } \\
\text { progressed to } 2 \text { h/week of other } \\
\text { instrumental training, ensemble } \\
\text { practice and performance }\end{array}$ & $\begin{array}{l}\text { Peak } \\
\text { latencies, } \\
\text { VA slope } \\
\text { (stop burst), }\end{array}$ & $\begin{array}{l}\text { Earlier latencies for peaks } V \text { (onset), } \\
\mathrm{E} \text {, and } \mathrm{F} \text { (consonant transition } \\
\text { period) in second year of training } \\
\text { relative to group with no } \\
\text { instrumental training. No significant } \\
\text { differences in latencies of peaks A, } \\
\mathrm{C}, \mathrm{D}, \mathrm{O} \text {, or slope of VA complex } \\
\text { (onset peak-trough) } \\
\text { No significant differences between } \\
\text { summed energy across ("middle } \\
\text { harmonics") 455-720 Hz, or across } \\
720-1154 \mathrm{~Hz} \text { ("high harmonics") }\end{array}$ \\
\hline $\begin{array}{l}\text { Strait et al. } \\
\text { (2011; Behavioral } \\
\text { and Brain } \\
\text { Functions) }\end{array}$ & $\begin{array}{l}\text { School-age } \\
\text { (8-13 years) } \\
\text { classified as } \\
\text { "good" and } \\
\text { "poor" } \\
\text { readers }\end{array}$ & $\begin{array}{l}\text { Repeated /da/ } \\
\text { (predictable } \\
\text { context) vs. } \\
\text { standard /da/ } \\
\text { interspersed with } \\
\text { /ba/, /ga/, /du/, /ta/, } \\
\text { shorter /da/, } \\
\text { higher-pitched /da/, } \\
\text { dipping pitch /da/ } \\
\text { (variable context) }\end{array}$ & $\begin{array}{l}\text { This was not a training study. } \\
\text { Measured at only one time point, } \\
\text { music aptitude was an aggregate } \\
\text { score that measured the ability to } \\
\text { compare melodies and rhythms }\end{array}$ & $\begin{array}{l}\text { Fast Fourier } \\
\text { Transform }\end{array}$ & $\begin{array}{l}\text { Stronger frequency encoding of } 200 \\
\text { and } 400 \mathrm{~Hz} \text { frequency components } \\
\text { in predictable vs. variable stimulus } \\
\text { contexts in good readers relative to } \\
\text { poor readers. Reading ability and } \\
\text { music aptitude scores correlated } \\
\text { with strength of encoding at both } \\
200 \text { and } 400 \mathrm{~Hz} \text {. No significant } \\
\text { differences in strength of } \\
\text { fundamental frequency encoding or } \\
\text { at any other harmonic frequencies }\end{array}$ \\
\hline
\end{tabular}

Bold indicates a significant difference between the musicians and non-musicians/control group in at least one measure.

*Indicates the same ABR measurement used in Kraus et al. (2014b).

RCTs involve certain design features, which Kraus et al. do not always fully exploit: for example, the difference in the size between the control $(n=18)$ and the experimental $(n=26)$ groups is unexplained, and may require a different statistical approach (Keselman and Keselman, 1990). The lack of an active control group prevents us from understanding whether the reported neural changes could be induced by an alternative enrichment activity (which is acknowledged by the authors), or whether a more focused language or literacy intervention would have yielded more effective results. It is also important to stress that while the paper makes specific claims about treatment effects for "impoverished brains" (e.g., individuals from low socio-economic backgrounds), no direct evidence of this impoverishment is provided, nor evidence that the effects on "impoverished" brains are any different to the effects on nonimpoverished brains, e.g., by including another control group. RCT methodology requires the reporting of the system used to generate the random allocation sequence, as well as mentioning participant drop-out rates, means, SDs, effect sizes and associated confidence intervals. Although an important first step, this paper falls some way short of suggested recommendations for the reporting of RCTs (Schulz et al., 2010).

To conclude, we have critiqued a recent high impact intervention study examining the effect of musical training on neural responses. Ineffective interventions provide false hope and waste financial resources (Strong et al., 2011) and therefore intervention programmes need to be evaluated rigorously. It is admirable to 
investigate the potential of community based musical training to improve neural coding of speech, but we argue that a stronger standard of evidence is required before concluding that musical enrichment enhances speech, language and literacy skills.

\section{ACKNOWLEDGMENT}

This work was supported by the Wellcome Trust (WT074414MA to S.K.S.).

\section{REFERENCES}

Aiken, S. J., and Picton, T. W. (2008). Envelope and spectral frequency-following responses to vowel sounds. Hear. Res. 245, 35-47. doi: 10.1016/j. heares.2008.08.004

Fuller, C. D., Galvin, J. J., Maat, B., Free, R. H., and Başkent, D. (2014). The musician effect: does it persist under degraded pitch conditions of cochlear implant simulations? Front. Neurosci. 8:179. doi: 10.3389/fnins.2014.00179

Hornickel, J., Skoe, E., Nicol, T., Zecker, S., and Kraus, N. (2009). Subcortical differentiation of stop consonants relates to reading and speech-innoise perception. Proc. Natl. Acad. Sci. U.S.A. 106, 13022-13027. doi: 10.1073/pnas.0901123106

Keselman, J. C., and Keselman, H. J. (1990). Analysing unbalanced repeated measures designs. Br. J. Math. Stat. Psychol. 43, 265-282.

Kraus, N., Slater, J., Thompson, E. C., Hornickel, J., Strait, D. L., Nicol, T., et al. (2014a). Auditory learning through active engagement with sound: biological impact of community music lessons in at-risk children. Front. Neurosci. 8:351. doi: 10. 3389/fnins.2014.00351
Kraus, N., Slater, J., Thompson, E. C., Hornickel, J., Strait, D. L., Nicol, T., et al. (2014b). Music enrichment programs improve the neural encoding of speech in at-risk children. J. Neurosci. 34, 11913-11918. doi: 10.1523/JNEUROSCI.188114.2014

Parbery-Clark, A., Skoe, E., Lam, C., and Kraus, N. (2009). Musician Enhancement for Speech-InNoise. Ear Hear. 30, 653-661. doi: 10.1097/AUD. 0b013e3181b412e9

Pitt, M. A., and Shoaf, L. (2002). Linking verbal transformations to their causes. J. Exp. Psychol. Hum. Percept. Perform. 28, 150-162. doi: 10.1037//00961523.28.1.150

Ruggles, D. R., Freyman, R. L., and Oxenham, A. J. (2014). Influence of musical training on understanding voiced and whispered speech in noise. PLoS ONE 9:e86980. doi: 10.1371/journal.pone. 0086980

Schulz, K. F., Altman, D. G., Moher, D., and Group, C. (2010). CONSORT 2010 Statement: updated guidelines for reporting parallel group randomized trials. Ann. Intern. Med. 152, 726-732. doi: 10.7326/0003-4819-152-11-201006 010-00232

Strait, D. L., Hornickel, J., and Kraus, N. (2011). Subcortical processing of speech regularities underlies reading and music aptitude in children. Behav. Brain Funct. 7:44. doi: 10.1186/17449081-7-44

Strait, D. L., O'Connell, S., Parbery-Clark, A., and Kraus, N. (2014). Musicians' enhanced neural differentiation of speech sounds arises early in life: developmental evidence from ages 3 to 30 . Cereb. Cortex 24, 2512-2521. doi: 10.1093/cercor/ bht103

Strait, D. L., Parbery-Clark, A., Hittner, E., and Kraus, N. (2012). Musical training during early childhood enhances the neural encoding of speech in noise. Brain Lang. 123, 191-201. doi: 10.1016/j.bandl.2012.09.001

Strait, D. L., Parbery-Clark, A., O’Connell, S., and Kraus, N. (2013). Biological impact of preschool music classes on processing speech in noise. Dev. Cogn. Neurosci. 6, 51-60. doi: 10.1016/j.dcn.2013. 06.003

Strong, G. K., Torgerson, C. J., Torgerson, D., and Hulme, C. (2011). A systematic meta-analytic review of evidence for the effectiveness of the "Fast ForWord" language intervention program. J. Child Psychol. Psychiatry 52, 224-235. doi: 10.1111/j. 1469-7610.2010.02329.x

Conflict of Interest Statement: The authors declare that the research was conducted in the absence of any commercial or financial relationships that could be construed as a potential conflict of interest.

Received: 10 October 2014; accepted: 12 November 2014; published online: 16 December 2014

Citation: Evans S, Meekings S, Nuttall HE, Jasmin KM, Boebinger D, Adank P and Scott SK (2014) Does musical enrichment enhance the neural coding of syllables? Neuroscientific interventions and the importance of behavioral data. Front. Hum. Neurosci. 8:964. doi: 10.3389/fnhum.2014.00964

This article was submitted to the journal Frontiers in Human Neuroscience.

Copyright (c) 2014 Evans, Meekings, Nuttall, Jasmin, Boebinger, Adank and Scott. This is an open-access article distributed under the terms of the Creative Commons Attribution License (CC BY). The use, distribution or reproduction in other forums is permitted, provided the original author(s) or licensor are credited and that the original publication in this journal is cited, in accordance with accepted academic practice. No use, distribution or reproduction is permitted which does not comply with these terms. 